\title{
Student and Faculty Perceptions of Professorial Attitudes: \\ A Study and an Invitation to Study
}

\author{
Andrew Short \\ Michael Kompf \\ Brock University
}

\begin{abstract}
This paper is a call for participation in an ongoing international comparative study of faculty and student perceptions of professorial attitudes, and how professorial attitude affects successful learning experiences in an academic setting. Student expectations of faculty and the institutions in which they teach vary by year and level of study. Further variations are apparent as the pressures of employment and finances weigh on students. Faculty expectations and understandings of students are also changing and may or may not match the realities experienced by students. Data were gathered at Brock University in 1997 that indicated several trends in professorial attitudes and behaviour. The original study was conducted via a traditional paper questionnaire. The current study employs a questionnaire designed to be accessed and completed over the Web. Implications of the study will be considered as related to the following three areas: theory, practice, and further research. The following questions will be used to study the implications in these areas. Are there any differences or similarities between and among different nationalities and cultures in attitudes towards the professorate? To what might differences and similarities in attitudes between and among cultural groups be attributed? What areas has the study identified that require further research? Information gathered will be concerned with the following findings as derived from the data to be collected: site by site analysis of survey items for students and faculty at each participating institution; and statistical comparisons between and among sites. Findings will be used to develop a model to foster understanding of underlying issues in effective and not so effective teaching in higher education. Also included is a review of literature concerning the areas of successful learning, personality, epistemology, and the practice of teaching and learning.
\end{abstract}

\section{Introduction}

This research extends an invitation to participate in a topic of national and

Andrew Short, ashort@ed.brock.ca, and Michael Kompf, mkompf@ed.brock.ca, are members of the Faculty of Education at Brock University 
international interest concerning potential differences in student and faculty perceptions of professorial attitudes and behaviours that lead to successful learning experiences. The underlying assumption is that while students and professors are co-constructors of knowledge in higher education, they do so differently because of the roles they fulfill in the university environment. That both learners and instructors are adults in adult learning settings also creates expectations for the classroom environment regarding behaviour and the responsibilities for both students and faculty. Our goal in this research is to promote an understanding of the extent to which the learning culture differentiates professorial behaviours as perceived by both students and instructors.

We also set out to develop a broad base for understanding by taking this study to the membership of an international teacher research organization. Additionally we provide full access to a web-based questionnaire (URL: http:// www.ed.brocku.ca/demeanor) and access to data already collected (please contact the authors). The use of a web-based methodology is innovative and will lead to a methodological study within this study. Feedback on methods will also be sought.

\section{On Professing}

There seem to be several inter-related themes at work in the higher education setting. These include but are not limited to issues such as: successful learning, personal expectations, personality, epistemology, and the notion of teaching and learning. The assumption is made here that learning and education are not equivalent terms. An education is something you "can get" or possess, while learning is a transformative activity in which members of a learning community, in this case students and their instructors, may change their attitudes or judgments through interaction with others in the learning environment.

\section{Successful Learning}

For the purposes of this study the most important facet of institutional learning relationships is student success. The definition of this term will be different both for individual students and for individual instructors. The notion of successful learning is multi-dimensional (Marsh, 1984) and rests upon the expectations of students, faculty, the institution, and other members of the greater community. A successful learning experience is one in which both students and instructors feel that their expectations have been confronted. Success in this case must involve both students and their instructors. In a sense, the co-construction of student learning depends upon the anticipation of 
events embedded in potential learning outcomes (Kelly, 1955).

The perception of successful learning is different for teachers and

students. Since both occupy different roles in the higher education hierarchy, it is expected that their perceptions of the environment and resultant construction of the learning process will differ. The institutional setting and the expectations of students further define the role and expectations of the instructor.

For the individual learner success could be defined as the acquisition of skills that make "meaningful work" possible and lead to an increase of choices that further one's life ambitions. The implications for the social world of the learner include the individual's ability to contribute to the functioning of society itself. This includes both direct economic impact and a philosophical/ political contribution by way of constructing knowledge and participating in democratic government (Association of Universities \& Colleges of Canada (AUCC), 1995).

\section{Personal Expectations}

The idea of personal success suggests many expectations. Students may view success as a pass, an ' $A$ ' grade, or achieving the top mark in class. Another expectation may be that a successful class is one in which learning takes place. Other expectations concern what students want from the instructor. The assumption is that instructors should meet the expectations of the students. As a result, the instructor is implicitly relied upon by students to devise a quantitative and evaluative measure of students' learning experiences, and must also facilitate learning in the classroom environment.

\section{Personality}

Personality is part of the affective domain that infiltrates all human experience including the teaching and learning relationships that exist in higher education. The personalities of both the student and the professor interact through individual behaviours and attitudes expressed in the execution of the interactions.

Research has suggested that the personality of the instructor is far more important in what students report as successful learning than the personality of the students (Abrami, Levanthal, \& Perry, 1982). Differences in instructor personality are expressed by behaviours used in the classroom to deliver curricular material. Murray, Rushton, and Paunonen (1990) suggest that professorial personality and subsequently behaviours affect teaching effectiveness. Moreover, they also intimate that professors' personalities are more suited to teaching certain disciplines and even specific courses (p. 260). 
When students have been asked to rate instructor personalities they have given the highest ratings to a professor whom:

was given to be a very healthy well integrated person, subjectively at ease with him[her] self, happy or content, using all his [her] constructive capacities, enjoying life without neurotic or psychotic maladjustment (Maslow \& Zimmerman, 1956, p.186).

Professors are also expected to be a capable expert in the field of study and must also know how to interact with students in an atmosphere of mutual respect (p. 186).

However, Maslow and Zimmerman (1956) also contend that students and faculty have different priorities and opinions when rating the professor. While students rely heavily on personality to make these judgments, faculty tend to use creativity expressed in materials delivery. Interestingly, even though students and faculty are said to use different criteria to judge teaching effectiveness, students and faculty often agree as to whom the best teachers are (p. 187).

\section{Epistemology}

The higher education setting is an artificial environment where knowledge is constructed. In this light a successful learning experience is one in which knowledge is successfully constructed. The relationships and goals of the parties involved in the learning process construct a unique epistemology.

There are many sets of goals expressed in this setting but this paper will consider those of the student and the professor. While students and professors construct knowledge in different ways, due to the unique nature of the academy professors have all at some point functioned as students. Professors have progressed through higher education to earn degrees and the expert status that enables them to lecture to students in a university setting. In some sense the professors have "been there". It has been reported in research that the further along to the professorial epistemology, the less certain knowledge becomes (Baxter-Magolda, 1996). For example, Baxter-Magolda contends that students who have completed undergraduate education and are enrolled in graduate or professional education consider the nature of knowledge to be much more flexible than do undergraduate students (p. 302).

The priorities for the epistemology of the faculty change from constructing knowledge as a learner to the means for the delivery of knowledge to students. According to some research professors should construct knowledge by questioning the material they deliver and more importantly, the practice of delivering the material (Knowles \& Cole, 1994). When professors 
construct knowledge with students they should emphasize that the nature of knowledge is uncertain and changeable (Jehng, Johnson, \& Anderson, 1993).

Far from a system of one-way interaction from instructor to student, there is a co-construction of knowledge in higher education settings. As professors shape the material for the students, the needs of the students will shape the classroom and to some degree the material. These needs influence the construction of knowledge. According to one researcher, if the classroom is to facilitate learning, student epistemologies should have the power to shape pedagogy (Baxter-Magolda, 1992). In order for the higher education setting to facilitate learning, the epistemologies of both students and instructors must be considered for effective teaching and learning to occur.

\section{Teaching and Learning}

If learning is important then the process by which it happens must also be a matter of concern. Why are we concerned with university teaching? As teaching and learning are highly interactive processes, attention is being paid to what the roles of both teachers and learners are in the co-construction of learning. Teaching has also been called "the most visible and recognizable activity in which those who work in universities engage" (Common, 1987). As evidence of the recognized importance of university teaching, consider that prior to 1974 no Canadian universities had instituted university teaching awards for faculty (p. 59).

Roles for instructors within higher education are not limited to teaching. Professors are also researchers. Levinson-Rose and Menges (1981) report that these roles need not be defined exclusively. That is, research can inform effective teaching (p. 403). These are jobs that the professor does-how does this concern others involved in the process? Professorial involvement includes more than carrying out the tasks such as teaching and research. The behaviour of the educator is crucial. According to Lowman (1994), instructors are both performers and motivators and as such their behaviours have a shaping influence on the learning experiences of students. Lowman provides a list of behaviours that are related to effective instruction and fall mostly in the affective domain (p. 139). Other research has been carried out in this area. For instance, factor analyses of the behavioural characteristics of instructors and their role in effective teaching have been recently reported (Krahn \& Bowlby, 1997). The roles that professors fulfill are tied to their expectations, and those of the university environment, of the work they do and are limited by the language used to describe the occupation (Bean, 1998). In short, instructors fulfill many roles in the pursuit of effective instruction including research, teaching, and more personal aspects such as examination of both self as educator and the practice of education. 
The role of student in higher education has changed in recent years moving towards a customer/provider dynamic. While learners have always had a stake in their learning, this shift in focus for the university has led to a struggle to justify teaching methods. As a result the definition of learning previously the domain of university instructors is now under increasing pressure from the customer/student. In this sense, if the needs of the student as perceived by hin/herself are not met then learning for the student has not taken place. Students identify one of their most important needs is that of learning itself. That is, some research has pointed to a correlation between students' satisfaction with higher education and the learning they perceive to be happening (Pike, 1993).

Out of this recent definition of learning has arisen the term "effective teaching". Focus on this has led to the implementation of new ways of teaching to satisfy the changing requirements; some demanded by increasing corporate influence including the push for universities to produce individuals to fill positions in the workplace, and others by students and their professors. Even so, researchers have reported that new teaching practices emerge from previous practices and that they are not dependent on how they enhance learning or anticipate needs of students (Amundsen, Gryspeerdt, \& Moxness, 1993). The nature of effective teaching is an elusive quality that can change shape and meaning for both the student and the instructor. It therefore seems defeatist to insist upon positivist logic to measure learning due to the complex nature of the learning teaching experience. That is, "there is no single criterion of effective teaching" (Marsh, 1984).

So where are we now as learners and teachers? We believe that we, the learning community, are still trying to figure out what good teaching is and what it is not. The answer is in the pursuit to meet the needs of our students who as a group will continue to change needs, wants, desires, and goals. Good teaching is that of which students ask "Are my needs being met, and if they change can the university accommodate me?", and where teachers ask "Am I meeting the needs of my students, how do I know this, and what can I do to address these needs?". Good teaching and learning therefore lies in the asking and examination of questions.

\section{Evaluation}

The question of student needs has led to more student participation in the evaluation of university teaching. This has changed the relationship between students and their professors. Common practice is that the instructor evaluates student academic performance. The student gets a grade at the end of the course of work and the student moves on to the next course. In the last 20 years, attention has been focused on the use of student evaluations of the 
instructors. Proponents argue that the consumers of the knowledge are the best individuals to evaluate teaching effectiveness (Feldman, 1976, 1979, 1988, 1989) as "only students observe a professor throughout a course" (Brodie, 1998).

Student evaluations of their professors are often used in hiring and tenure decisions in some universities. This allows the student a tremendous amount of power in shaping the teaching practices of the university. While this is an important matter of customer satisfaction and of the meeting of individual needs, it is also rife with potential bias. For example one researcher has found that "When grades varied markedly across sections of the same course, the professor assigning the highest grades with least studying received highest evaluation" (Brodie, 1998). In essence Brodie asserts that "easy" professors are rated as "good" teachers by their students (p. 17).

If we examine students needs we see that an "easy" professor serves one student need while detracting from another. For example, while good grades may lead the student to a professional job and an elevated role in society, the student may not be fulfilling the role of learner as questioner. The other potential complication is that the professor may be less concerned with the learning process of the student than with a positive evaluation. Evaluations can be important sources of feedback (Marsh, 1991) but attention must be paid to their possibly ambiguous nature.

\section{Background of the Study to Date}

Data were gathered at Brock University that indicated several trends in professorial attitudes and behaviour. Trends related to the following demographic variables for students: year of study, respondents age, gender, and part-time vs. full-time study. There are nine demographic items each for students and faculty. Both subject groups responded to the same 38 nondemographic or attitudinal variables. The questionnaire was a "scantron" form no. 899 on which demographic information was gathered first. The attitudinal items were based upon a five-point Likert-type scale with " 1 " representing least important and " 5 " being most important.

While findings will not be reported in depth, interesting trends seem apparent and want substantiation through additional study. For example, differences were noted in students responding as to level of study, age, and gender.

In 1998 the same survey was distributed at DeVRY Technical Institute in Toronto, Ontario. DeVRY is not considered a university but is a technological trades school. These data were then compared to the Brock data. Differences were found both in faculty and student responses to the survey. Differences in the faculty responses included the variables concerning critical 
thinking and relaxed atmosphere, while in the students' responses differences were found for variables such as the charisma and self assurance of the faculty member.

The differences between the college and university responses could be seen as cultural differences. If the previous comparisons between Brock University and DeVRY Technical Institute suggest a cultural influence on professorial behaviour, then it would seem possible that an international study would express other cultural differences. By comparing these data we would attempt to construct a checklist of professorial behaviours that differ within and between cultures.

\section{Research Plan}

The purpose of this project is to conduct an international comparative study of professorial attitudes, and to determine how they affect successful learning experiences in an academic setting.

\section{Overview}

Colleagues from several international universities have been invited to participate in this research. The Newsletter of the International Study Association on Teachers and Teaching (ISATT) has been used to invite participation from interested colleagues (URL: http://www.ISATT.org).

There are two populations to be studied: faculty and students. Colleagues at participating universities will collect data by way of a custom designed web-based questionnaire. There are two surveys different only in the demographic information being collected-one for students and one for faculty. The surveys will be distributed to the target international universities from Brock University. This study will aim for a 10 percent sample of the total population of each cohort from each of the subject institutions.

Colleagues at international institutions interested in participating in the study will receive an information package describing the intent of the study and all of the measures involved in gathering the data. Colleagues will disseminate this information to the volunteer participants at the target institution. Two letters will be included. One will ask for the participation of faculty to be distributed within the target institution by the colleagues. The other will be a notice to request the participation of students. Colleagues within the target institutions will be asked to arrange for their distribution. In this way all potential participants will be informed of the intent and demands of the administration of the study. As well, acknowledgment of participation and appreciation for said participation will also be sent. Individual forms will remain confidential. Overall results will not identify any individual participant. 
All notices and information are to be sent to the target institutions by electronic means if possible.

\section{Data Collection}

The data will be collected by colleagues at the target universities by way of web-based survey instrument. (URL: http:/www.ed.brocku.ca/demeanor) There are two forms which differ only in the demographic information being collected, one for students and one for faculty. (The password for both surveys is "andrew". The login for the student survey is "demeanors" and for faculty: "demeanorf", all entries are without quotation marks). The data will then be collected by the international colleagues and mailed back to Brock University for compilation and analysis.

\section{Analysis}

There will be three phases in the data analysis. Phase One: Comparisons will be done intra-university for all of the participating subject institutions. That is, comparative analysis between student and faculty responses on attitudinal variables. Phase Two: The second phase will consist of general comparisons between all of the subject institutions to elicit significant differences in responses. Phase Three: The third phase will test certain demographic trends through all subject institutions and compare their influences. For example, year of study, age of respondent, and part-time vs. full-time status.

\section{Method}

\section{Web Epistemology}

As stakeholders in the process of education, we are being faced with certainty of both theoretical and practical applications of technology. One of the most rapidly growing technologies in institutes of higher education is the web. The web is a tool that is gaining favour in universities to provide on-line course development, distance delivery of those courses, voice and video production capabilities, and as evidenced by this study, the opportunity to conduct research.

While many tasks can certainly be accomplished with greater apparent efficiency than non-web methods, there is a question of ideology implied in its functions. No technology, from the book and the pen to the personal computer and its applications such as the web, is free of ideological baggage. The apparatus used to carry out a task should not be considered benign, but should be contemplated in terms of its effect on the task being carried out (Postman, 1986). 
Often, the web is defined in terms of what it can do rather than what it is. That is the web is seen more often as a technique than a technology. The web is a creator not only a conveyor of knowledge. Consider how quickly web sites can be changed, updated, or removed altogether. The information is unstable, forever changing, and subject to manipulation. In this way the web can be called a post modern methodology for carrying out tasks.

In short the web challenges our assumptions about knowledge and how it is stored. Rather than cohesive and whole, as in a book, the web accesses information from millions of sources that are at best inconsistent in the quality of information offered. This is not to say that the web should not be used in academia, quite the contrary. The web may be useful to universities because they should by their nature question the information they receive and the apparatus that delivers it. There are real material advantages to using the web. For this study the development of the web page questionnaire was not only cheaper than the paper version but quicker as well. Also, copious mail outs are not necessary with a web-based survey and so valuable research funding can be used elsewhere. The most important benefit is that data entered on the web survey are much closer to being compiled and analyzed than those entered onto paper questionnaires. An important caveat to remember is that whatever method you choose to gather and use information the method carries an ideology that affects the content.

\section{Outcome and Implications}

There will be three shared levels of findings for participants: a site-by-site analysis of survey items for each of students and faculty; statistical comparisons between and among sites; and a synthesis that will assist development of a regionally and culturally sensitive "Principles of Successful Practices" to foster understanding of underlying issues in effective teaching and learning in higher education.

Implications of the study will be discussed concerning the following three areas: theory, practice, and further research through the following questions. What, if any, are the differences or similarities between and among different nationalities and cultures in attitudes towards the professorate? To what might differences and similarities in attitudes between and among cultural groups be attributed? What implications might findings carry for whether or not theory relates to practice? What areas has the study identified that require further research?

We invite the participation of individuals, or groups of individuals in this research that will assist understanding the importance of issues that underlie teaching and learning in higher education. 


\section{References}

Abrami, P.C., Levanthal, L., \& Perry, R.P. (1982). The relationship between student personality characteristics, teacher ratings, and student achievement. Journal of Educational Psychology, 74, 111-125.

Amundsen, C, Gryspeerdt, D., \& Moxness, K. (1993). Practice centered inquiry: Developing more effective teaching. The Review of Higher Education, 16(3), 329-353.

Association of Universities and Colleges of Canada (AUCC). (1995, June). A primer on performance indicators. Ottawa, ON: AUCC, Research File.

Baxter Magolda, M.B. (1992). Students' epistemologies and academic experiences: Implications for pedagogy. The Review of Higher Education, 15(3), 265-287.

Baxter Magolda, M.B. (1996). Epistemological development in graduate and professional education. The Review of Higher Education, 19(3), 283304.

Bean, J.P. (1998). Alternative models of professorial roles: New languages to re-imagine faculty work. Journal of Higher Education, 69(5), 496-512.

Brodie, D.A. (1998). Do students report that easy professors are excellent teachers? The Canadian Journal of Higher Education, 28(1), 1-20.

Common, D.L. (1987). Teaching in universities: The power to touch. The Canadian Journal of Higher Education, 17(3), 59-66.

Feldman, K.A. (1976). Grades and college students' evaluations of their courses and teachers. Research in Higher Education, 4, 69-111.

Feldman, K.A. (1979). The significance of circumstances for college students' ratings of their teachers and courses. Research in Higher Education, 10, 149-172.

Feldman, K. A. (1988). Effective college teaching from the students' and faculty's view: Matched or mismatched priorities. Research in Higher Education, 28(4), 291-344.

Feldman, K.A. (1989). Instructional effectiveness of college teachers as judged by teachers themselves, current and former students, colleagues, administrators, and external (neutral) observers. Research in Higher Education, 30(2), 137-194.

Jehng, J.J., Johnson, S.D., \& Anderson, R.C. (1993). Schooling and students' epistemological beliefs about learning. Contemporary Educational Psychology, 18, 23-35.

Kelly, G.A. (1955). The psychology of personal constructs. New York: Norton.

Knowles, J.G.. \& Cole, A.L. (1994). Researching the "Good Life": Reflections on the professorial practice. The Professional Educator, 17 (1), 49-60. 
Krahn, H., \& Bowlby, J.W. (1997). Good teaching and satisfied university graduates. The Canadian Journal of Higher Education, 27(2-3), 157180.

Levinson-Rose, J., \& Menges, R.J. (1981). Improving college teaching: A critical review of research. Review of Educational Research, 5l(3), 403-434.

Lowman, J. (1994). Professors as performers and motivators. College Teaching, 42(4), 137-141.

Marsh, H.W. (1984). Students' evaluations of university teaching: Dimensionality, reliability, validity, potential biases, and utility. Joumal of Educational Psychology, 76(5), 707-754.

Marsh, H.W. (1991). Multidimensional students' evaluations of teaching effectiveness: A test of alternative higher-order structures. Journal of Educational Psychology, 83(2), 285-296.

Maslow, A.H., \& Zimmerman, W. (1956). College teaching ability, scholarly activity, and personality. Journal of Educational Psychology, 47, 185189.

Murray, H.G., Rushton, J.P., \& Paunonen, S.V. (1990). Teacher personality traits and student instructional ratings in six types of university courses. Journal of Educational Psychology, 82(2), 250-261.

Pike, G.R. (1993). The relationship between perceived learning and satisfaction with college: An alternative view. Research in Higher Education, 34(1), 23-40.

Postman, N. (1986). Amusing ourselves to death: Public discourse in the age of show business. New York: Penguin Books. 